\title{
Improving the level of development of speech competence of students in higher educational institutions through the implementation of the author's program
}

\author{
Olga Ovsyannikova ${ }^{1, *}$, Igor Bocharnikov ${ }^{2}$, and Svetlana Bobrova ${ }^{3}$ \\ ${ }^{1}$ National Security Research Center, 15 Plekhanov str., Building 2, 119571, Moscow, Russia \\ ${ }^{2}$ Bauman Moscow State Technical University, 105005, Moscow, Central Administrative District, \\ Basmanny district, 2-ya Baumanskaya str., 5, building 1, Moscow, Russia \\ ${ }^{3}$ Moscow State Regional University, 10A Radio str., 105005, Moscow
}

\begin{abstract}
The developed method was tested at the Moscow State Regional University. As a result of its testing, the authors identified the reasons for the development of students ' speech competence and described the necessary methods to improve its level. The analysis of the obtained data showed that in the experimental group, the level of development of speech competence after the implementation of the program for the formation of speech competence of students significantly increased in comparison with the results obtained in the control group. These data demonstrate a gradual change in values in the direction of improving the level of speech and language training of students from the first year to the third. In the course of the study, a pattern was formulated, which consists in the fact that the level of speech competence depends more on the creation of the necessary conditions for the professionalization of speech activity. The author's program widely uses texts of a professional nature, as well as tasks aimed at developing skills and abilities to work with analytical information, with professional service documentation, compiled mainly in official business, scientific styles. The presented didactic material for classes is mainly compiled from professional texts in order to familiarize students with the specifics of these texts and develop skills and abilities to work with such materials.
\end{abstract}

\section{Introduction}

At present, the problem of the development and formation of speech skills, which form the basis of the speech competence of future specialists studying at a higher educational institution, is of particular relevance. It should be noted that there is a tendency to worsen the quality of students ' speech training. This situation is caused by various reasons that weaken the quality of speech training. The emerging contradiction between a significant decrease in the level of language training and literacy, which characterizes modern

\footnotetext{
*Corresponding author: mimaal@yandex.ru
} 
education, and the need to improve the level of professional training of future specialists, including their speech and language competence, for the successful performance of professional tasks, and revealed the need to develop and implement the author's program for the formation of speech competence of students of the university.

The conducted research is based on the theoretical provisions of the activity approach, which was formed based on the generalization of psychological and pedagogical research on the problems of activity. This approach is represented by the works of B.G. Ananyev [1] P.Ya. Galperin [2], V.V. Davydov [3], A.N. Leontiev [4]. The theories of personality of Russian and foreign scientists, which consider the problems of its development and formation, are also taken as a basis. These theories are considered in the works of L. S. Vygotsky [5], S.L. Rubinstein [6], A.V. Petrovsky [7]. The research is based on the modern concepts of personal development in higher education, set out in the works of A.G. Asmolov [8], V.S. Mukhina [9], as well as on the concepts of personal and professional development of students in higher education (L.I. Shumskaya [10], A.A. Derkach [11]) and on the concept of the role of the educational environment in the development of personality (V.A. Yasvin [12]).

\section{Methods}

Significant research methods that determine the level of development and formation of the speech competence of a university student are theoretical and methodological analysis of the problem, comparative analysis, comparison, modeling, various types of empirical research, mathematical methods of data processing that allow us to identify stable relationships, trends and patterns of certain changes, as well as to summarize the research material. However, the main method of research was the method of observation and training and formative experiment. They helped to identify the initial level of speech competence, and then, after the implementation of the author's program, to determine the formed indicators of the level of speech development of students. This study was conducted on the basis of the Moscow State Regional University. It was attended by 25 students.

To analyze the personal characteristics of students in the study of speech skills, various approaches were used. It should be noted the use of a block approach, which identifies individual blocks of personality. The initial block takes into account the genetic indicators of neuropsychiatric processes (intensity, speed, rhythm, endurance) set by nature. These characteristics are used to describe the language personality of the student, since they affect the speed of reading, writing, speaking and other processes. The next block takes as a basis the higher mental functions, which are complex mental processes formed during the socialization of the individual. This block is represented by memory, attention, and personality perception. As for the «language personality» of the student, we mean the ability to process texts, that is, with the help of these mental categories, the processes of folding, retelling, and interpreting information are carried out.

In addition to the block approach, the motivational-dynamic approach was also considered. This approach assumes that the characteristics of the student's personality can be considered from the point of view of the hierarchy of levels of needs or motives of the individual. It is no accident that the determining motive of educational activity is the motive of self-actualization and self-realization, which is closely related to the conditions of further professional activity and affects it. Therefore, in the formation of speech competence, this particular motive, which is the main one among students, was taken into account.

In this author's program, an approach based on the study of individual abilities was also taken as a basis. Therefore, the program offers various types of tasks aimed at the successful formation of the «language personality» of the student. Extroverted students are provided with tasks based on oral texts. These include the following: modeling different 
speeches depending on the stylistic coloring, conducting discussions on this topic, since the speech of an extrovert is characterized by such features as spontaneity, high speed of expression, transition from one topic under consideration to the next.

It should be noted that the activity of an introvert is conditioned by his subjective views. Introverted students are offered to work with various written texts, namely: writing tests, annotations and abstracts, texts based on a certain sample, as well as texts of official business and scientific speech styles.

\section{Results}

In the process of conducting ascertaining and forming experiments, some features of the process of forming the speech competence of university students were identified.

Indicators of speech competence largely depend on various individual psychological characteristics of the individual, which include speed, flexibility and logical thinking, a certain level of intelligence development, the presence of diplomacy, rigidity, as well as emotional stability and other factors. It is possible to trace the dependence of speed, flexibility, logical thinking on the level of development of the intellectual abilities of the student's personality. Auditory memory for information is also closely related to the level of development of human intelligence. It should be noted that sociability correlates with the level of intelligence development, and the higher the level of sociability in a person, the greater the indicator of intellectual abilities. The level of intelligence development is more closely related to the indicators of speed, flexibility, logical thinking and auditory memory for information.

The tendency of the formation of speech competence is a significant increase in the knowledge, skills and skills of speech competence of students from the first year to the third.

The study revealed the fact that the improvement of the level of knowledge, skills and skills of speech competence of students depends on what factors affect students in the process of forming speech competence.

The experimental group that participated in the study included 25 respondents, their level of development of speech competence significantly increased, on average by $20 \%$. The control group consisted of 25 respondents. The increase rate averaged $17 \%$.

We will analyze the indicators of the average level of development of speech competence in both the control and experimental groups before (h) and after (k) the use of the author's program in the classroom (Table 1).

The indicators of the average value of the level of development of speech competence in the control and experimental groups before and after the application of the author's program are clearly presented in the diagrams.

The diagram clearly shows the level of formation of speech competence of students in the experimental group (Fig. 1). 
Table 1. Indicators of the average level of development of speech competence in the control and experimental groups before and after the use of the author's program.

\begin{tabular}{|c|c|c|c|c|c|}
\hline $\begin{array}{l}\text { Signs of the respondents } \\
\text { 'speech competence }\end{array}$ & Stage & $\begin{array}{l}\text { Control } \\
\text { group }\end{array}$ & $\begin{array}{c}\text { Change } \\
\text { indicators }\end{array}$ & $\begin{array}{c}\text { Experimental } \\
\text { group }\end{array}$ & $\begin{array}{c}\text { Change } \\
\text { indicators }\end{array}$ \\
\hline \multirow{2}{*}{ SS1- spelling skill } & elementary & 4.2 & \multirow{2}{*}{0.4} & 4.3 & \multirow{2}{*}{0.6} \\
\hline & test & 4.6 & & 4.9 & \\
\hline \multirow{2}{*}{$\mathrm{P}$ - punctuation skill } & elementary & 3.8 & \multirow{2}{*}{0.4} & 3.9 & \multirow{2}{*}{0.5} \\
\hline & test & 4.2 & & 4.4 & \\
\hline \multirow{2}{*}{ GS - grammar skill } & elementary & 4.2 & \multirow{2}{*}{0.3} & 4.3 & \multirow{2}{*}{0.5} \\
\hline & test & 4.5 & & 4.8 & \\
\hline \multirow{2}{*}{ SS2- speech skill } & elementary & 4.4 & \multirow{2}{*}{0.3} & 4.1 & \multirow{2}{*}{0.8} \\
\hline & test & 4.7 & & 4.9 & \\
\hline \multirow{2}{*}{ C - confidence } & elementary & 3.9 & \multirow{2}{*}{0.3} & 4.09 & \multirow{2}{*}{0.71} \\
\hline & test & 4.2 & & 4.8 & \\
\hline \multirow{2}{*}{$\begin{array}{l}\text { SP-structured } \\
\text { presentation }\end{array}$} & elementary & 3.2 & \multirow{2}{*}{0.4} & 3.05 & \multirow{2}{*}{1.27} \\
\hline & test & 3.6 & & 4.3 & \\
\hline \multirow{2}{*}{$\begin{array}{l}\text { GP - generality of } \\
\text { presentation }\end{array}$} & elementary & 3.0 & \multirow{2}{*}{0.2} & 2.9 & \multirow{2}{*}{1.3} \\
\hline & test & 3.2 & & 4.2 & \\
\hline
\end{tabular}

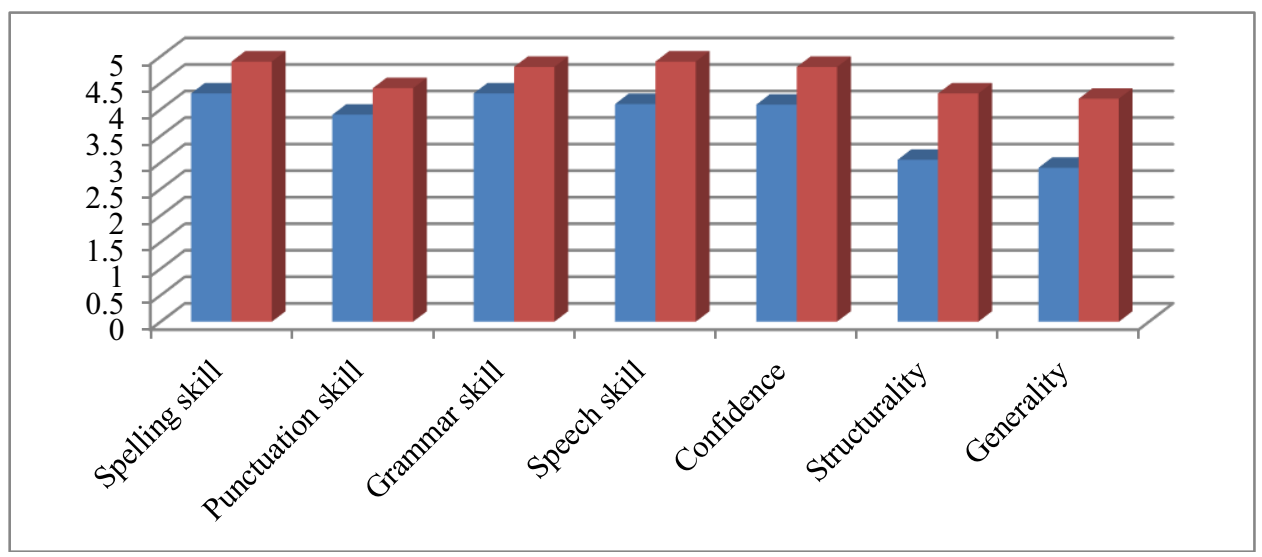

Fig. 1. Indicators on the speech competence of respondents in the experimental group.

We will compare the indicators of the level of speech competence of respondents in the control group, clearly shown in Figure 2.

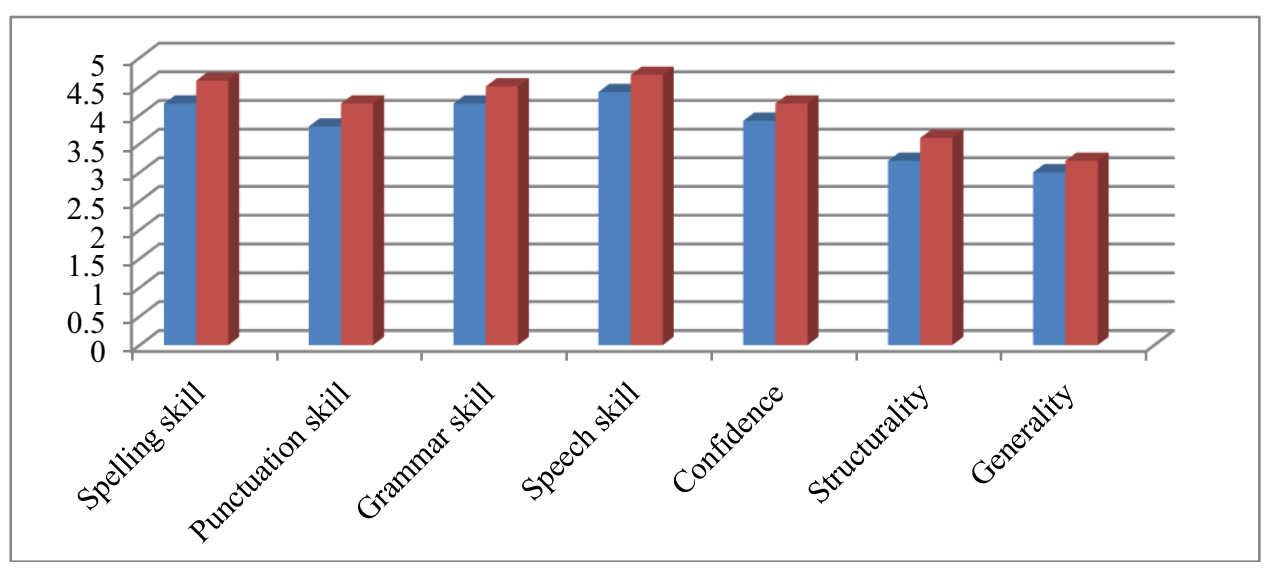

Fig. 2. Indicators on the speech competence of the respondents in the control group. 
It should be noted that the indicator of the level of development of spelling skills in the experimental group increased by $13 \%$, and in the control group - by $7 \%$. The indicator of the level of development of punctuation skills increased by $15.8 \%$ in the experimental group, and in the control group - by $11.2 \%$. The indicator of the level of development of grammatical skills in the experimental group increased by $15 \%$, and in the control group by $7.9 \%$. The indicator of the level of development of speech communication skills in the experimental group increased by $18 \%$, and in the control group - by $10.5 \%$. The indicator of the level of reliability of the presentation of information in the text in the experimental group increased by $19 \%$, and in the control group - by $8.7 \%$.

The value of the level of structured presentation of information in the text in the experimental group increased by $42 \%$, and in the control group - by $9.8 \%$. The value of the level of generalization of information in the text in the experimental group increased by $41.5 \%$, and in the control group - by $10.3 \%$.

Consequently, the results of the formative experiment show that the value of the level of development of speech competence has changed significantly in the process of applying the author's program, specially created for students. This can be seen in the tables and diagrams below. Quantitative values demonstrate that the developed program significantly affects the formation of the speech competence of university students.

As can be seen from the tables and diagrams, in the course of the ascertaining experiment, both quantitative and substantive indicators of the formation of the respondents ' speech skills and abilities were identified. These data demonstrate a gradual change in the values towards improving the level of speech and language training of students.

\section{Discussion}

On the basis of this study, it should be emphasized that the level of speech competence of university students improves in the course of training according to the author's methodology from the first year to the third in the process of implementing the program for the formation of speech competence.

Improving the effectiveness of training, as well as the development of communication skills and the formation of speech competence of students of the university contributes to working with professional texts, performing tasks containing analytical materials, professional documentation, which is written in the official business and scientific styles.

The study showed that the level of development of speech competence in the context of professionalization of speech activity in the process of studying at a university significantly improves.

The development and formation of skills and abilities to work with analytical materials, which are texts, reports, annotations, as well as abstracting, reviewing, drawing up a test plan, that is, all types of work with a secondary test, are effectively aimed at the formation of speech competence, preparation for further professional activity.

The following indicators of the formation of speech competence in students were identified, which are:

a) developed oral and written speech;

b) the ability to develop and execute official documents;

c) working with texts of various styles;

(c) Handling large amounts of information;

d) the ability and skills to compose your own texts in different styles, depending on the desired goal;

e) rhetorical skills and oratorical skills;

f) compliance with the norms (orthoepic, lexical, word-forming, morphological, syntactic, spelling and punctuation) [13]. 
Note that each of the corresponding indicators, having its own level of development, as a whole, derive an integral indicator of the students ' speech competence.

One of the essential parameters of speech competence is highly developed speech. This indicator is characterized by the ability to correctly, accurately and expressively convey your thoughts using various means. It is also defined in the ability to offer the most correct, appropriate, appropriate in meaning for each specific case, the language means for expressing one's thoughts. Speech determines the mandatory adherence to and implementation of norms and rules, which include consistency, content, structure, evidence, persuasiveness, and clarity [14].

The author's program for the development of speech competence emphasizes that all tasks should be of a professional orientation. Therefore, the main focus should also be on working with business documentation.

To the business documentation with which the student works, a number of requirements should be imposed, which can include such as:

a) the presence of standardization and unification;

b) following the lexical, grammatical, and stylistic norms that ensure the accuracy and consistency of the presentation of the material;

c) mandatory unambiguity of words, phrases and terms;

d) the presence of a neutral tone of presentation.

The author's program provides for the allocation of levels of development of students ' speech competence, according to which tasks are compiled for further implementation. According to these criteria, three levels of speech competence formation are defined - high, medium, and low.

A high level of formation of speech competence has the following features:

a) the teacher is aware of the importance of speech competence in professional activity, has a competent oral and written speech;

b) the student knows the norms of the language, which include orthoepic, lexical, wordforming, morphological, syntactic, spelling and punctuation;

c) the student knows the criteria of speech competence, which include accuracy, correctness, relevance, clarity, purity, richness and diversity, expressiveness of speech, knows speech etiquette and formulas of polite communication;

d) the student knows the features of the official business style as a variety of the Russian literary language, its purpose, features, and features of the functioning of genres;

e) has a high level of oratory skills and excellent rhetorical skills.

The average level of speech competence has the following features:

a) the student has an insufficient level of development of oral and written speech;

b) does not have sufficient knowledge of the norms of the language, which include orthoepic, lexical, word-forming, morphological, syntactic, spelling and punctuation;

c) does not have sufficient knowledge of the criteria of speech competence, which include accuracy, correctness, relevance, clarity, purity, richness and diversity, expressiveness of speech, knows speech etiquette and formulas of polite communication;

d) the student does not know enough about the features of the official business style as a variety of the Russian literary language, its purpose, features, and features of the functioning of genres;

e) has an average level of oratory skills and rhetorical skills.

The low level of speech competence formation has the following features:

a) the student has an illiterate oral and written speech;

b) the student has a superficial knowledge of the norms of the language, which include orthoepic, lexical, word-forming, morphological, syntactic, spelling and punctuation;

c) the student has a low level of proficiency in the criteria of speech competence, which include accuracy, correctness, relevance, clarity, purity, richness and diversity, 
expressiveness of speech, superficially knows speech etiquette and formulas of polite communication;

d) does not know the official business style as a kind of Russian literary language, its purpose, signs, features of the functioning of various genres;

e) has a low level of oratory skills and mediocre rhetorical skills $[15,16]$.

Given the cumulative achievement of certain human Sciences, who studied the specifics of communicative activities of the student, in the structure of formation of speech competence of students there are certain levels that were also taken into account in the process of developing the author's program, held testing:

a) linguistic (language) level, which includes the norms of written and oral Russian literary language (the rules of orthoepy, vocabulary, grammar, stylistics);

b) the cultural and historical level, which involves a set of information about national or cultural and historical features of the use of certain linguistic means characteristic of a particular society. These include information of a national-cultural nature, information about nationally determined connotations of words, and others;

c) situational level, which prescribes mandatory compliance with the norms of the Russian literary language, as well as possession of theoretical information about the conditions for using certain language tools, the ability to choose from the presented speech options the most suitable in terms of meaning, expressive, relevant, stylistically and situationally relevant, the most effective for social and professional speech interaction;

e) professional level, which involves the use of speech and language tools necessary in professional activities.

After conducting research, it is possible to formulate a pattern, which consists in the fact that the level of speech competence depends more on the creation of the necessary conditions for the professionalization of speech activity.

The author's program widely uses texts of a professional nature, as well as tasks aimed at developing skills and abilities to work with analytical information, with professional service documentation, compiled mainly in official business, scientific styles. The presented didactic material for classes is mainly compiled from professional texts in order to familiarize students with the specifics of these texts and develop skills and abilities to work with such materials [17].

\section{Conclusions}

The features identified in the course of the study provide a basis for identifying and justifying the levels of development of speech competence of university students and their corresponding characteristics, in order to adjust the author's program for the development of speech skills.

The formation of speech competence is a multi-faceted work that requires deep and comprehensive study. The development of the author's program for the formation of speech competence of students at the university with the use of competence and activity approaches involves taking into account the characteristics of students, among which the student's self-assessment, practical work experience, willingness to learn, and understanding of the need to apply the studied material in practice in order to solve professional and communicative tasks are essential. The analysis of the data obtained during the study revealed the following: in the experimental group, the difference in the level of development of speech competence after applying the author's program for the formation of speech competence of students increased significantly, if we compare the results obtained in the control group. 


\section{References}

1. B.G. Anan'ev, Selected psychological works (Moscow, Pedagogika, 1980)

2. P.Ya. Galperin, The Main results of research on the problem of «formation of mental actions and concepts» (Moscow, 1965)

3. V.V. Davydov, Theory of developmental education (Intor, Moscow, 1996)

4. A.A. Leont'ev, D.A. Leontiev, E.E. Sokolova, Activity, consciousness, personality (M., 2005)

5. L.S. Vygotsky, Sobranie sochineniy 6.3 (Moscow, Pedagogika, 1983)

6. S.L. Rubinstein, Fundamentals of General psychology (St. Petersburg, Piter, 2010)

7. A.V. Petrovsky, Questions of history and theory of psychology. Selected works (Moscow, Pedagogika, 1984)

8. A.G. Amsmolov, Personality psychology: cultural and historical understanding of a person (Moscow, 2019)

9. V.S. Mukhina, Personality: Myths and Reality: an alternative view, a systematic approach, innovative aspects (Moscow, National Book Center, 2019)

10. L.I. Shumskaya, Diagnostics of the educational process in higher education

11. A.A. Derkach, Social psychology and acmeology: formation of the image: monograph (Moscow, Publishing House of NOU SGI, 2006)

12. V.A. Yasvin, Training of pedagogical interaction in the creative educational environment (Moscow, 1997)

13. O.A. Ovsyannikova, S.V. Bobrova, I.V. Bocharnikov, E3S Web of Conferences. VIII International Scientific and Practical Conference "Innovative technologies in science and education» (ITSE 2020) (2020)

14. O.A. Ovsyannikova, M.A. Mishcherina, I.V. Bocharnikov, E3S Web of Conferences. VIII International Scientific and Practical Conference "Innovative technologies in science and education» (ITSE 2020) (2020)

15. I.V. Bocharnikov, Bulletin of the Moscow State Humanitarian and Economic Institute 1(13), 71-75 (2013)

16. O.A. Ovsyannikova, Optimization of the process of studying particles with computer support: dis. ... kand.ped. nauk (Moscow, 2003)

17. E.M. Markova, J.V. Bobrova, S.V., Mishcherina, Technologies for the development of speech-thinking abilities of schoolchildren in the process of learning the Russian language. I caught up (Brno, 2014) 